\section{The Winds of Change}

\author{
M. Castillo, Editor-in-Chief
}

A of May 2014, the American Society of Neuroradiology (ASNR) had 702 women members. Although it is difficult to determine who the first women neuroradiologists were, ASNR's data base offers the possibility of determining who our initial female members were. Among the first 20, easily recognizable names due to their academic achievements include Drs Dietrich (\#3), Davis (\#4), Byrd (\#12), Cohen (\#13), Osborn (\#19), and Donovan Post (\#20). Of them, Dr Osborn is an ASNR Past President (1988-1989) and Dr Donovan Post, an ASSR Past President (1999-2000). From the time of its founding in 1962, ASNR has had only had 3 women Presidents apart from Dr Osborn as follows: Dr Hudgins (2005-2006), Dr Meltzer (2010-2011), and Dr Schaefer (2012-2013). In 2015, Dr Loevner will become its fifth female President. However, in ASNR, as in the rest of medicine, the winds of change are coming our way. At the time of this writing, I serve as the society's First Past President and 3 of the 6 members of the Administrative Committee are women and of 23 Executive Committee members 9 are women, the highest proportions ever. In AJNR, 3 out of 6 Senior Editors are women (Drs Schaefer, Fischbein, and Tanabe).

If one looks at medical school applicants in the United States, in 1969, 9\% were women; however, by 2010, the American Association of Medical Colleges (AAMC) reported that $48 \%$ of medical degrees were awarded to women. ${ }^{1}$ Nursing has always been a female vocation, and continues to be; $94.6 \%$ of registered nurses are women. In the past, pharmacology was mostly a man's occupation; however, today over $60 \%$ of pharmacists are female. ${ }^{2}$ Women's participation in medicine did not significantly increase until the 1970s when our government banned discrimination on the grounds of sex and when the AAMC made a point of supporting their participation in medical education. In England, nearly $60 \%$ of current medical students are female (it reached $62 \%$ in 2003 ) and women make up $40 \%$ of physicians, $42 \%$ of general practitioners, and nearly $30 \%$ of specialists. ${ }^{3}$ British women seem to prefer general practices such as pediatrics (40\%) more than surgical specialties $(<10 \%)$ and similar statistics are found for Canadian physicians. The United States is catching up and nearly $44 \%$ of medical students are now female (in other countries the current female-to-male ratio is 3:2). In more liberal countries such as France and Spain, women make up 58\% and $64 \%$ of doctors under the age 35 , respectively. ${ }^{2}$

Warning: Before you continue reading, I must tell you that I am not casting judgment here, just summarizing what is found in the literature.

Some argue that women in medicine are less productive than men and debate if the rise of women in medicine will accentuate the shortage of physicians and access to health care. Workplace differences between males and females are consistent across different countries so culture and religion have little influence on

http://dx.doi.org/10.3174/ajnr.A4075 how medicine is practiced by either sex. In general, women are less likely to work excessive hours, they retire at the expected age (or at a younger age), and see lesser numbers of patients; conversely, they are better communicators and spend more time in preventive care. Because women patients seem to seek women physicians, more female doctors should equal better outcomes and life expectancies for women; however, studies have found that overall, the number of physicians per population regardless of sex has little to do with female life expectancy. In addition, countries such as Canada and Japan with a low physician density show longer lives for women than countries with higher densities of female physicians such as the United States and the Netherlands. ${ }^{4}$ However, because on the whole more physicians means more female physicians and more primary care practitioners, the overall benefits of adding more women to the medical workflow may eventually have a positive effect in prolonging life expectancy. The Organization for Economic Cooperation and Development has gathered data that support the notion that countries with the highest strength in primary care have better outcomes related to all-cause mortality, all-cause premature mortality, and cause-specific premature mortality. This report does not address the role of women in these outcomes, but because they represent a disproportionate presence in primary care, there must be some relationship.

In 2 controversial articles, the British Medical Journal discussed the issue of too many female medical graduates. Against female medical graduates, Dr McKinstry offered the following statements $^{5}$ :

1) Because females concentrate in family friendly specialties, their presence will tilt the balance between generalists and specialists, leading to a smaller number and shortage of the latter.

2) Females are more likely to work part-time and their work is disrupted by pregnancies and child rearing. Moreover, $50 \%$ of females continue to work part-time even when their children become older, while most men, regardless of age, work full-time.

3) Females generally retire earlier than age 60 (in psychiatry, they tend to retire on average at age 55).

4) Mothers tend to publish significantly less than men and childless women.

Arguing for the role of women in medicine, Dr Dacre stated ${ }^{6}$ :

1) Medicine needs to attract the best and brightest, and women as a whole do better on undergraduate and postgraduate examinations (in reality these differences are minimal and of questionable significance as are the results of many other examinations).

2) Medicine is a caring profession and women are much more engaged in patient care than men.

3) Despite their large number in medicine, women are underrepresented in academia. Their numbers decrease with increasing ranks; in England and the United States, only 11\% and 15\% of professorships, respectively, are held by women. Only $10 \%$ of department Chairs are women in the United States. 
Local politics may also favor the presence of women in medicine. In Europe, the current trend is to restrict the working week for health service professionals to 48 hours (The European Working Time Directive). ${ }^{1}$ More female doctors working part-time will facilitate achieving these reduced schedules with enough physicians to support the needed workforce.

Increasing female participation in professional activities is occurring at all levels and in most countries, even the most conservative. Saudi Arabia now allows women to work in areas where women feel that communicating among each other is better. Most specialized women's apparel shops now must have female sales associates. ${ }^{7}$ In that country, women represent $17 \%$ of the current workforce and their participation increased $280 \%$ in the last 10 years, while nearly $60 \%$ of all university students are women. More than half of all $\mathrm{PhDs}$ in that country are now given to females. ${ }^{2}$ Although Saudi professional women still make less money than their male counterparts, that is not the case everywhere. In Brazil, $30 \%$ of women make more money than their husbands. ${ }^{2}$

In December 2013, Time magazine published an article entitled: "2013: The Year Men Became Obsolete?"8 That short article offers a startling glimpse at the winds of change: In 2013, 57\% of all bachelor's degrees were earned by women as well as $60 \%$ of master's degrees and $52 \%$ of doctorates. The number of women with degrees could be higher but many universities have chosen an arbitrary threshold of $60 \%$ as their cutoff for female admissions. While the participation of women in the workforce increased to $6.2 \%$ (1980-2012), men's participation went down by $7.2 \%$ during the same period. What are men doing? Well, according to that article they are pouring concrete, laying bricks, tarring roofs, and excavating sewage lines, among other dirty and dangerous métiers. These latter observations come from the famous Munk Debates on the obsolescence of males.*

But let us go back to women in medicine and particularly in radiology. Some 22 years ago when I came to the University of North Carolina, at least half of our residents were female, but after a few years, we had just men and now, out of 31 residents, 7 are female (roughly 23\%). In the last 3 years, out of a total of 12 neuroradiology fellows, 4 have been female, so again roughly a similar proportion between specialty and subspecialty. These numbers match those reported in the literature, that is, about $24 \%$ of US radiologists are women. Why is that, when more than $50 \%$ of US medical students are female? The explanations offered follow: Fear of irradiation during childbearing age, too little patient contact, too many years of extra training, and a highly competitive specialty with decreasing job opportunities upon graduation. $\mathrm{Cu}-$ riously, females also find working in dark rooms unappetizing. The American College of Radiology is aware of this and has created a Commission for Women that is charged with researching and identifying ways to attract and retain more women in radiology. When compared with general medicine, the numbers of

\footnotetext{
* The Munk Debates are held biannually in Toronto to discuss major policy issues. The organization was funded by Peter Munk (Chairman of the world's largest gold mining operation) in 2008.
}

women in radiology are decreasing. In 1995, 28\% of radiology residents were women; however, by 2000 , this number had decreased to $22 \%$. A survey published in the American Journal of Roentgenology shows that after internal medicine (18\%), radiology $(15 \%)$ is the most popular specialty selected by female medical students. ${ }^{9}$ That article lists intellectual stimulation as one of the reasons that radiology is chosen by both women and men. Another reason that is not mentioned in that article may be regular hours. Another specialty with regular hours, gastroenterology, may shed some light onto this factor. The number of female gastroenterologists has gone up from $5 \%$ to $30 \%$ mostly due to its regular scheduled hours. ${ }^{2}$ The changes being experienced by the medical profession are a subject of close scrutiny. From 1976 to 1979 , only 6 articles exploring the role of women in medicine were published; between 2005 and 2009, there were $212 .^{10}$

Of the 30 professions that will add the most jobs in the next 10 years, women already dominate $20 .^{2}$ The salaries for full-time men, when adjusted for inflation, have increased 28\% from 1969 to date, but most women still make less money than men. Women, ages 25-35 make on average 20\%-25\% less than men (US $\$ 37,000$ versus $\$ 49,000$ in 2012). This may be, at least in part, because women still make up most low-paid workers. Unfortunately, the same pattern is seen in academia where female researchers earn US \$6000-\$13,000 less than men, and in departments of medicine where they on average earn US $\$ 15,000$ less than men across all ranks. ${ }^{11}$ So although the winds of change are blowing our way, perhaps they need to blow stronger and more fairly.

\section{REFERENCES}

1. Women in medicine. http://en.wikipedia.org/wiki/Women_in_ medicine. Accessed January 9, 2014

2. Pharm girls. How women remade the economy. In: Rossin H. The End of Men and the Rise of Women. New York: Riverhead Books; 2012:113-45

3. Elston MA. Women in medicine. The future. www.rcplondon.ac.uk/ sites/default/.../women-and-medicine-summary.pdf. Accessed January 9,2014

4. Phillips SP, Austin EB. The feminization of medicine and population health. JAMA 2009;301:863-64

5. McKinstry B. Are there too many female medical graduates. Yes. BMJ 2008;336:748-49

6. Dacre J. Are there too many female medical graduates. No. $B M J$ 2008;336:749-50

7. Zoepf K. Shopgirls. The New Yorker. December 23, 2013. http:// www.newyorker.com/reporting/2013/12/23/131223fa_fact_zoepf. Accessed January 9, 2014

8. Paglia C. 2013: the year men became obsolete? Time. December 30, 2013:26

9. Fielding JR, Major NM, Mullan BF, et al. Choosing a specialty in medicine: female medical students and radiology. AJR Am J Roentgenol 2007;188:897-900

10. Riska E. Gender and medical careers. Maturitas 2011;68:264-67

11. Mangan $\mathrm{K}$. Women in academic medicine: equal to men, except in pay. The Chronicle of Higher Education. January 9, 2014. http:// chronicle.com/article/Women-in-Academic-Medicine-/64892/. Accessed January 9, 2014 